\title{
Políticas públicas educacionais no Rio Grande do Sul: indicadores para discussão e análise na área das Altas Habilidades/Superdotação
}

Nara Joyce Wellausen Vieira*

\section{Resumo}

No presente artigo, são discutidas e analisadas as ações de implantação da proposta de política pública educacional no Rio Grande do Sul, com base nos indicadores formulados por Rosângela Prieto (2001, 2002, 2003): Diretrizes Legais; Concepção Teórica; Organização e Funcionamento do Ensino; Gestão do Sistema de Ensino; Financiamentos na Área da Educação e Condições de Trabalho do Professor. Destaca-se, ao final, um novo paradigma de educação especial e a importância da proposição de políticas públicas que considerem esse modelo, assim como é assinalada a importância da articulação intersecretarias para que as ações de política pública se fortaleçam.

Palavras-chave: Educação Especial. Políticas Públicas. Altas Habilidades/ Superdotação.

\section{Public educational policy in Rio Grande do Sul: Indicators for discussion and analysis in the area of the High Abilities/ Giftedness}

\begin{abstract}
The actions to settle the proposal of public educational policy in Rio Grande do Sul state (Brazil) are discussed and analyzed in this paper, based upon Prieto's indicators (2001, 2002, 2003): legal guidelines; theoretical conception; educational organization and functioning; educational system management; investments in the educational field; and teachers' working conditions. Finally, a new paradigm of Special Education and the relevance of proposing public policies considering this model are highlighted, as well as the importance of an articulation among the different state departments to reinforce the public policy actions.
\end{abstract}

Keywords: Special Education. Public Policies. High Abilities/Giftedness

Professora Doutora do Departamento de Educação Especial, Centro de Educação, Universidade Federal de Santa Maria, Santa Maria, Rio Grande do Sul, Brasil. 


\section{Introdução}

As políticas públicas educacionais na área das altas habilidades/ superdotação, no Brasil, caracterizam-se pela descontinuidade com que os programas de atendimento educacionais são oferecidos a esses alunos. Em geral, quando ocorrem, estão localizados nas capitais, exigindo que as famílias que residem no interior dos estados se desloquem para obter orientações de como auxiliar no desenvolvimento dos potenciais de seus filhos.

Não se pode afirmar, contudo, que não existe uma política para este grupo social, quando se entende que "[...] todas as decisões que envolvem o coletivo da população, principalmente aquelas de natureza econômica e mesmo as que deixam de ser tomadas e implantadas quando necessárias, são políticas por sua própria natureza (FÁVERO; HORTA; FRIGOTTO, 1992, p.5, grifos meus). Então, considerando as palavras desses autores, a política para as altas habilidades/superdotação é não ter uma política. Cabe perguntar: por que a dificuldade de propor políticas para este segmento da população? Por que este sujeito é pensado somente na Educação?

Mais do que uma queixa, a situação aqui apresentada é uma denúncia. Uma denúncia que traz subjacente os mitos e as crenças errôneas existentes em relação a este grupo social e que são referidos, na literatura, como uma das principais causas dos óbices na implantação e implementação do seu atendimento. Os mitos contribuem na formação das barreiras atitudinais que dificultam o entendimento das necessidades singulares desses indivíduos. Não é minha intenção discutir neste artigo um assunto de natureza tão importante e exaustivamente analisado na literatura. Cabe, entretanto, assinalar que as crenças errôneas estão fundamentadas no hábito de não examinar criticamente os fatos referentes a determinados temas, evidenciando que é "[...] nossa ignorância propriamente dita, que é mais prejudicial ao conhecimento" (ALENCAR; FLEITH, 2001, p. 86). Estes "saberes" sobre tantas coisas não verdadeiras e baseados num conhecimento de senso comum constituem os entraves reais para um (re)conhecimento do sujeito com altas habilidades/superdotação e de suas necessidades.

Apesar dessa realidade, desde 2003 o Rio Grande do Sul vem desenvolvendo uma política pública na área da educação com a proposta de atendimento educacional às altas habilidades/superdotação, efetuada através de uma parceria com a Secretaria Estadual de Educação e FADERS. São 24 Salas de Recursos para Desenvolvimento de Potenciais, em 17 municípios do Rio Grande do Sul, descentralizando, dessa forma, o atendimento, sediado anteriormente somente em Porto Alegre (GERMANI; COSTA; VIEIRA, 2006a, 2006b).

Em 2005, foi proposta a política pública para as altas habilidades/ superdotação em nível nacional, através da criação dos Núcleos de Atividades para as Altas Habilidades (NAAHS), nas 27 Unidades da Federação e no Distrito Federal. 
Tomando por base esse cenário, este texto discutirá os indicadores para a realização e análise de Políticas Públicas na Área da Educação, de acordo com os aspectos apresentados por Prieto (2001, 2002 e 2003). A exposição dos indicadores foi organizada para responder a duas questões centrais: subsidiar os gestores dos sistemas de ensino com alguns elementos essenciais em suas propostas de políticas e traçar algumas trajetórias sobre como provocar/produzir mudanças, com vistas a assegurar qualidade de ensino para todos os alunos.

O propósito dessa discussão não é esgotar um tema tão complexo, nem realizar um levantamento envolvendo exaustivamente todos os elementos implicados na elaboração de políticas públicas. O que se pretende é contribuir com o debate sobre a temática, discutindo a proposta feita no Rio Grande do Sul.

Porém, antes de iniciar a análise, faz-se necessário definir o que se entende por Políticas Públicas. Na opinião de Giugliani (2007, p. 6):

\begin{abstract}
Políticas Públicas são ações coordenadas com o objetivo público, isto é, coletivo. São políticas de Estado e não de governo e pressupõe uma capacidade de impacto no sentido da construção da cidadania. Existem para garantir os direitos humanos [...] e devem promover transformações sociais que trabalhem diretamente com a promoção da cidadania e provoquem a participação ativa da sociedade com a sua exceção e efetividade. (Grifos meus).
\end{abstract}

Os grifos destacam aspectos importantes para a concepção de políticas públicas, pois se entende que discutir e analisar políticas públicas vai além do elencar uma série de leis, decretos e resoluções que normalizam os direitos das pessoas com altas habilidades/superdotação. Portanto, em primeiro lugar, cabe ressaltar a importância de que as Políticas Públicas se constituam por ações coordenadas com objetivo público. Em outras palavras, para que uma política transforme-se em ações positivas deve estar amparada pelas demais ações desenvolvidas na secretaria de estado e/ou do município a que pertence, bem como necessita estar articulada com as demais ações das outras secretarias. A parceria de umas ações com as outras favorece o enriquecimento e crescimento de todas.

Em segundo lugar, políticas públicas são ações de Estado e não de governo. Quem trabalha em serviços públicos sabe que a cada troca de governo mudam-se todas as ações de políticas e iniciam-se novas propostas, as quais, na maioria das vezes, não têm tempo suficiente para se solidificarem em quatro anos de gestão. Nessa situação, as diretrizes legais contribuem para a efetivação das ações, apesar da troca dos governos. 
Por último, grifei a participação ativa da sociedade, destacando principalmente o envolvimento das associações civis organizadas, tais como ConBraSD instituição nacional e a AGAAHSD, regional, entidades engajadas e atentas na luta da defesa dos direitos das pessoas com altas habilidades/superdotação. Não há como entender construção e promoção da cidadania sem a participação direta das pessoas envolvidas.

\section{Do direito à educação e do atendimento educacional especializado}

O Brasil é rico em leis que garantem os direitos educacionais das pessoas e reconhecem suas singularidades, evidenciando que a visão progressista de nossos legisladores está mais adiantada do que a da maioria dos educadores brasileiros, que resistem em reconhecer a diversidade e a singularidade de aprendizagem de cada aluno (DELOU, 2007).

A Constituição da República Federativa do Brasil (BRASIL, 1988), o Estatuto da Criança e do Adolescente (ECA) (BRASIL, 1990) e a Constituição do Estado do Rio Grande do Sul (RIO GRANDE DO SUL, 1989) são dispositivos legais que asseguram a efetivação dos direitos referentes à vida, à saúde, à alimentação, à educação, ao esporte, ao lazer, à profissionalização, à cultura, à dignidade, ao respeito, à liberdade e à convivência familiar e comunitária de todas as pessoas.

Na educação, a Lei de Diretrizes e Bases da Educação Nacional (LDBN) (BRASIL, 1996) e o Plano Nacional de Educação (BRASIL, 2001) garantem a proposição de currículos, métodos, recursos educativos e organizações específicos para atender às necessidades do aluno, garantindo oacesso e permanência com qualidade, na escola.

O Decreto 6.571 (BRASIL, 2008) institui a Política Nacional de Educação Especial na Perspectiva da Educação Inclusiva. O Parecer CNE/CEB n.13/ 2009 e a Resolução CNE/CEB N.04/2009 (BRASIL, 2009a, 2009b) regulamentam esse decreto. Nessa perspectiva, o Atendimento Educacional Especializado (AEE) é definido como "[...] o conjunto de atividades, recursos de acessibilidades e pedagógicos organizados institucionalmente, prestado de forma complementar ou suplementar à formação dos alunos no ensino regular" (BRASIL, 2009b). O AEE é destinado aos alunos com Deficiência, com Transtornos Globais do Desenvolvimento e com Altas Habilidades/Superdotação e deve integrar a proposta pedagógica da escola, envolver a família e articular-se com as demais políticas públicas; ser desenvolvido nas Salas de Recursos Multifuncionais da própria escola ou em outra do ensino regular, sempre no turno inverso ao da escolarização (BRASIL, 2009b).

Como é possível perceber, a legislação brasileira delineia com clareza as ações de políticas públicas na área da educação. No entanto, somente o texto legal não é suficiente para sua instituição. O que falta, então? Falta o conhecimento por parte dos professores e familiares das leis que garantem os direitos do alunado da educação especial e, por esse desconhecimento, não é exigido o seu cumprimento. 
Pela experiência vivida com a implantação da Política Pública Educacional no estado do Rio Grande do Sul, a legislação foi o elemento favorecedor para que as ações propostas em final de governo continuassem, mesmo após a entrada do novo governo. Em outras palavras, pela instituição legal das Salas de Recursos nas escolas, foi possível garantir a continuidade das ações nos mesmos moldes previstos no projeto inicial.

Para finalizar esta seção, faz-se necessário destacar que apesar de tantas legislações existentes e citadas nesta seção, ainda faltam legislações específicas e afirmativas que garantam a esses alunos, principalmente aos de classe socialmente desprivilegiadas, o transporte gratuito ao atendimento, a reserva de vagas nas universidades públicas e gratuitas, dentre outras necessidades, pois, apesar de serem "superdotados", não são "super" em tudo e necessitam da ajuda externa para desenvolver seu potencial.

\title{
Da permanência com qualidade na escola e do acesso aos níveis mais elevados do ensino
}

Prieto $(2001,2003)$ ressalta a importância de focalizar o Plano de Governo defendido pelos gestores em cada esfera de governo, quando se trata de analisar a política pública de atendimento às pessoas que apresentam altas habilidades/superdotação. Nesse sentido, concepções como educação de qualidade para todos e educação inclusiva devem estar bem explicitadas como objetivos precípuos nos compromissos assumidos pelos governos estaduais e municipais (PRIETO, 2001).

No entanto, dada a complexidade da temática, faz-se necessário explicitar também as concepções de inteligência e de altas habilidades/ superdotação que subsidiam tais programas. $\mathrm{Na}$ atualidade, aponta-se para definições que reconheçam a convergência das várias dimensões humanas e que reúnam não somente as habilidades abstratas, mas também as sociais, corporais, musicais, de liderança, dentre outras. Para Ourofino e Guimarães (2007, p. 44):

\begin{abstract}
A superdotação devido à sua característica multidimensional abarca uma infinidade de variáveis e características que se manifestam simultaneamente, mediando os comportamentos superdotados. As concepções teóricas-empíricas, ao apresentarem visões diferenciadas e até mesmo conflitantes sobre a superdotação, acentuam ainda mais a complexidade desse objeto de estudo e imprimem a necessidade de uma compreensão cada vez mais holística e distanciada da visão unidimensional associada ao conceito de QI.
\end{abstract}

Tal pensamento justifica a importância da inclusão das concepções teóricas subjacentes nas propostas de políticas públicas, pois são elas que direcionam todo o processo de identificação e atendimento educacional dos alunos com altas habilidades/superdotação. 
Nesse sentido, anterior à implantação da política pública educacional no Rio Grande do Sul, foi realizado um Curso de Capacitação de 420 horas para professores da rede estadual. Posteriormente, foram realizadas reuniões nas quais participaram representantes das Coordenadorias Regionais de Educação, diretores e orientadores educacionais das escolas que receberam as salas de recursos e professores capacitados. Tais reuniões tiveram como objetivo tornar comum as concepções subjacentes à proposta, bem como favorecer a construção conjunta de uma prática com esses alunos, evitando que, como referem Ourofino e Guimarães (2007), visões diferenciadas e até mesmo conflitantes sobre as altas habilidades/superdotação acentuassem ou dificultassem ainda mais a implantação da ação. Concepções teóricas harmônicas e claras devem embasar o trabalho, oferecendo segurança aos professores numa área tão complexa.

Os professores que trabalham nas 24 salas de recursos utilizam o referencial teórico proposto pelas Inteligências Múltiplas de Howard Gardner e a Teoria de Superdotação de Joseph Renzulli. É possível que, com o avanço de seus estudos e com um conhecimento maior alicerçado em sua prática, um ou outro professor possa aprofundar-se em outras teorias, para embasar suas atividades. A proposta libera cada profissional para percorrer seu próprio caminho. Porém, é importante destacar que as novas concepções teóricas e empíricas não devem perder de vista o enfoque das altas habilidades/superdotação como um todo, não privilegiando somente a área cognitiva, assim como deve haver sintonia entre a teoria e a prática.

\section{Da articulação de ações e do planejamento conjunto entre as diversas esferas do governo}

Em 1998, formou-se, na FADERS, um grupo intersecretarias, composto por representantes de diferentes secretarias, sociedade civil organizada (AGAAHSD) e equipe técnica da FADERS. Por essa experiência, verificou-se que a falta de articulação entre as diferentes secretarias de governo e/ou municípios favorece para que existam programas semelhantes entre elas. Os programas poderiam se tornar mais fortes e articulados se existisse uma comunicação direta entre as secretarias, um intercâmbio de ações e de planejamento entre as diversas esferas do governo estadual e/ou municipal.

Trabalhar considerando o paradigma da educação inclusiva implica que o setor da educação especial nas secretarias de educação participe do planejamento conjunto com as diferentes modalidades e níveis da educação, não se constituindo um apêndice. Desse modo, é importante observar como são elaborados os projetos e as ações na área de educação, se há espaço reservado ao planejamento conjunto para os diversos níveis e modalidades de ensino, evitando a sobreposição e duplicação de investimentos em pessoal e recursos financeiros, entre outros. 


\section{Da construção de novas perspectivas e busca de novos olhares}

A democratização da gestão dos sistemas de ensino deve ser a chave mestra para que novas perspectivas sejam construídas e novos olhares sejam focados. Um planejamento educacional democrático deve prever a criação de espaços e incentivar a participação da sociedade civil. Para tal, são formados conselhos gestores, tais como os Conselhos de Educação e os Conselhos das Pessoas com Deficiência e Altas Habilidades/Superdotação, os quais estão formados por representantes do governo e também da sociedade civil. Ao garantir organização e funcionamento articulado com os seus representados, expressam as posições, expectativas e necessidades coletivas voltadas para 0 bem comum (PRIETO, 2002, 2001).

Nas escolas, esse cenário democrático favorece a construção de um projeto político pedagógico que assegure as mudanças necessárias para oferecer uma educação de qualidade para todos. Essas mudanças passam pela autonomia administrativa, financeira e pedagógica das escolas, implicando numa organização do currículo que respeite as características próprias dos alunos com altas habilidades/superdotação, garantindo a aprendizagem e o desenvolvimento dos seus potenciais.

Nesse sentido, cabe destacar alguns princípios importantes e que devem ser respeitados, independentes das modalidades ou das alternativas de atendimento especificadas na proposta pedagógica da escola: o atendimento educacional deve estar integrado ao contexto do projeto educativo da escola e não ser encarado como uma atividade extracurricular com objetivo meramente lúdico ou ocupacional; todas as propostas de oficinas, seminários, concursos, dentre outras, devem ser estendidas a todos os alunos da escola; a família deve participar de todas as fases do processo; inclusão de ações continuadas e sistemáticas com outras áreas, como a cultura, trabalho, assistência social, ciência e tecnologia, desporto, dentre outras.

\section{Do provimento adequado dos recursos financeiros para uma ação efetiva}

O indicador financiamento para proposta de política pública educacional, segundo Prieto $(2001,2002)$, é um tema desafiante, pois diversos aspectos envolvem essa discussão. O primeiro deles é assegurar uma proposta de política pública que garanta a educação numa perspectiva inclusiva, "[...] requer prever o equacionamento adequado de recursos financeiros, sem o que dificilmente daremos conta dessas tarefas" (PRIETO, 2001). Nesse sentido, é um indicador importante a relação entre o discurso e a prática, ou seja, se "[...] o sistema mantém coerência entre o discurso inclusivo e a prática, provendo adequadas condições de atendimento dessa população" (PRIETO, 2001). Outros dois aspectos importantes são a prevalência do uso das verbas públicas em instituições públicas e a previsão dos custos adicionais e/ou vinculados aos projetos de atendimento educacional. 
Na proposta inicial, estavam previstas duas grandes ações que envolviam previsão orçamentária financeira: a primeira delas era a instalação do espaço físico para o atendimento educacional nas escolas da rede pública estadual, e a segunda, o acompanhamento dos professores através de reuniões sistemáticas.

No que se refere à análise do primeiro item, observou-se que a instalação do espaço físico nas escolas estaduais foi bastante complicada. Em primeiro lugar, porque, segundo algumas diretoras, não havia espaço físico disponível nas escolas. Dessa forma, em algumas instituições, as salas de recursos eram salas que funcionavam como depósito de materiais inservíveis. Em muitas delas, o Conselho de Pais e Mestres da escola foi envolvido na ação e contribuiu de forma significativa para a instalação do atendimento, inclusive com trabalho braçal de seus membros, como, por exemplo, com a pintura das paredes das salas. Essa situação reforça a necessidade do envolvimento dos conselhos na gestão dos sistemas de ensino, já falado anteriormente. Da mesma forma, tal fato reforça que, apesar desses indicadores serem apresentados de forma separada, eles estão interligados.

A outra questão referente à instalação do espaço físico foi a previsão de verbas para contribuir na segurança da sala. Como o material didático distribuído era de valor (computadores, impressoras, filmadoras, máquinas fotográficas digitais, dentre outros), a preocupação dos gestores das escolas era de que o material poderia ser roubado. Infelizmente, a invasão dos espaços pedagógicos e o vandalismo são realidades sofridas pelas escolas gaúchas. Pode-se observar, então, que, apesar de haver previsão da instalação do espaço físico na implantação do projeto, não havia uma previsão para a manutenção desse espaço, requerendo, portanto, que as escolas reorganizassem seus gastos, incluindo a manutenção da sala. Como se pode imaginar, no primeiro ano de instalação, esse processo foi difícil, mas com a inclusão do atendimento educacional na proposta pedagógica da escola a situação se acomodou nos anos seguintes.

A segunda ação prevista envolvendo planejamento e gerenciamento do dinheiro público foi o acompanhamento dos professores através de reuniões sistemáticas. A implantação da política educacional previa acompanhamento sistemático aos gestores e professores, com objetivo de analisar, discutir e compartilhar as dificuldades e as facilidades encontradas no cotidiano do trabaIho. No entanto, não foi possível realizar as reuniões com a periodicidade esperada, acontecendo uma vez a cada semestre nos anos iniciais e anuais nos últimos anos. Desde 2009, não há nenhum encontro desse grupo com a equipe técnica da FADERS, responsável pelo acompanhamento e avaliação do projeto. Tal situação é justificada em relação aos gastos que envolvem esse acompanhamento, pois, além dos gastos com passagens rodoviárias, há também os gastos com hospedagem e alimentação dos envolvidos no projeto. Entende-se que o número de pessoas envolvidas é grande, em torno de 75 pessoas. No entanto, como refere Prieto (2001), 
Políticas públicas educacionais no Rio Grande do Sul: Indicadores para discussão e análise na área das Altas Habilidades/Superdotação

[...] se a proposta defendida é construir espaços educacionais de qualidade para todos os alunos, é preciso prever os custos adicionais ou subvinculados que serão necessários aos projetos de atendimento educacional especializado oferecidos na escola comum (alunos, professores, gestores, funcionários, pais etc.) ou em outros espaços. Isso envolve, dentre outros itens, investir na admissão e qualificação de profissionais bem como a provisão de materiais e equipamentos específicos.

Com esse pensamento de Prieto (2001), introduz-se o último indicador referido pela autora e que trata das condições de trabalho dos professores.

\section{Do domínio do saber para um fazer consciente, responsável e seguro}

A capacitação e a formação continuada dos gestores e professores foram pensadas de duas formas: através do acompanhamento sistemático referido no item acima e de cursos de formação continuada de curta duração. Porém, antes de analisar esses dois itens, faz-se necessário explicar o motivo da inclusão dos gestores nessa formação. Desde a implantação da proposta, as discussões envolveram os gestores da educação e os professores capacitados. Considerando-se uma proposta de educação inclusiva, tal procedimento justifica-se por si só. Porém, o professor capacitado não faz o trabalho sozinho, ele necessita do gestor da educação especial na Coordenadoria Regional de Educação e do diretor da escola para garantir a formação da rede interna e externa que dará sustentação ao seu atendimento e garantirá o sucesso de sua atividade. Através do domínio do saber sobre as necessidades dos sujeitos com altas habilidades/superdotação é possível desmanchar as ideias errôneas que povoam o imaginário social sobre esses alunos.

Retornando à discussão sobre o primeiro indicador - capacitação e formação continuada dos professores -, já foi analisado parte desse indicador no item anterior. Cabe somente acrescentar que se entende que a descontinuidade no acompanhamento aos professores não se justifica somente pela falta de previsão financeira, mas também traduzem o descuido com a formação em serviço e a ideia de que o aprofundamento e a discussão da temática já não são necessárias quando existe um trabalho sedimentado. Esse pensamento não está de acordo com o da Equipe Técnica da FADERS, tampouco com o dos professores envolvidos na proposta, que buscam orientação e reivindicam, via on-line, novos encontros.

O compartilhamento das atividades foi o ponto alto desses encontros, pois, como cada um dos professores encontra-se em regiões diferentes do estado, tendem a sentir-se sozinhos e isolados na ação. Alguns conseguiram estabelecer uma rede mútua de contato com a equipe técnica e outros colegas com os quais têm mais afinidades e que os fortalece. Outros, porém, não estabeleceram essa rede interativa. Tal realidade parece traduzir que são nesses 
espaços de compartilhamento que os profissionais se sentem seguros ao iniciar uma nova ação.

Contraditoriamente, parece não haver possibilidade de articulação do estudo com o repensar e resignificar a prática durante a jornada de trabalho do professor e de outros profissionais da educação. Como afirma Prieto (2001), a capacitação não se dá somente pela oferta de cursos esporádicos, mas na busca constante do saber. Reconhece-se a necessidade de espaços de formação para essa construção do saber, porém, torna-se imprescindível que o professor entenda que a formação continuada faz parte do fazer profissional de todos os profissionais e que somente a graduação e cursos de curta duração não garantem o acesso à atualização de seu conhecimento.

Deixamos por último os dois indicadores polêmicos: salários adequados à responsabilidade profissional e plano de carreira adequado à realidade local. Não temos elementos suficientes para a análise do plano de carreira. No que se refere aos salários, o professor da rede estadual e que trabalha na educação especial no Rio Grande do Sul ganha $50 \%$ a mais do salário base. Isso significa que todas as 24 professoras tiveram uma melhoria em seu salário ao assumirem as salas de recursos para os alunos com altas habilidades/ superdotação. Se por um lado essa situação parece positiva, pois os incentiva a melhorar sua atividade profissional, por outro, ela gera conflitos entre os colegas da escola, que justificam que eles trabalham com 30 ou 40 alunos, enquanto os professores das salas de recursos atendem no máximo 6/7 crianças de cada vez. Esta situação também promove dificuldades para o professor capacitado no aliciamento dos professores regentes para o atendimento educacional em sala de aula, promovendo o enriquecimento e aprofundamento curricular dos alunos de sua classe. A justificativa do professor regente para manter-se alijado do processo é que o professor capacitado tem formação e recebe a gratificação para cumprir esse papel.

\section{Do pensar a educação como um instrumento de desenvolvimento pessoal e social}

Para finalizar essa discussão, é possível afirmar que quando se pensa em políticas públicas para o atendimento educacional especializado para alunos com altas habilidades/superdotação, faz-se necessário, em primeiro lugar, entender que os indicadores aqui apresentados separadamente, representam somente uma forma didática de estudo, pois, na realidade, eles acontecem de maneira integrada e articulada.

Em segundo lugar, como foi bem demonstrada por Prieto $(2001,2002$, 2003), a análise de políticas para a melhoria da educação envolve fatores para além dos limites do plano legal. O plano legal pode ser entendido como o fator propulsor e de garantia dos direitos, mas sem os outros indicadores essa análise torna-se estéril. 
Em terceiro lugar, para a implantação efetiva de políticas públicas educacionais, faz-se necessário debater, analisar e buscar o consenso na elaboração de um projeto pedagógico inspirado na educação da diversidade, que ofereça a cada criança aquilo que ela necessita para desenvolver sua potencialidade e respeite os diferentes estilos de aprendizagens, ritmos, interesses e capacidades de cada aluno.

Por fim, espera-se que, ao relatar a realidade do processo de implantação da proposta de política educacional para as altas habilidades/superdotação no Rio Grande do Sul, tenha sido possível contribuir com a discussão de um tema tão importante e desafiante; assim como tenha alertado aos gestores sobre a importância da articulação entre as ações das diferentes secretarias, pois essa articulação permitirá a formação de uma rede interna que pode dar sustentação ao trabalho.

Repetindo o que já foi assinalado anteriormente, para que uma política transforme-se em ações positivas, ela deve estar amparada pelas demais ações desenvolvidas na secretaria de estado e/ou do município a que pertence, bem como deve estar articulada com as demais ações das outras secretarias. Não é possível deixar de citar que a formação da rede de apoio também deve se estender pelos recursos existentes na comunidade, articulando ações com as diferentes instituições que envolvem as áreas do desporto, das artes cênicas e plásticas, da música, da dança etc. A formação dessa rede promove a parceria de uma ação com as outras, possibilitando um maior enriquecimento e crescimento de todas.

\section{Referências}

ALENCAR, E. S.; FLEITH, D. de S. Superdotados: determinantes, educação e ajustamento. São Paulo: EPU, 2001.

BRASIL. Ministério da Educação. Secretaria de Educação Especial, Parecer CNE/CEB N.13/2009, aprovado em 03 de junho de 2009. Brasília: MEC/SEESP, 2009a. Disponível em: http://portal.mec.gov.br/index.php?option=com content\&view=article\&id $=12745 \&$ ltemid=866. Acesso em 06 de novembro de 2009.

. Ministério da Educação. Secretaria de Educação Especial, Resolução CNE/CEB 04/2009, aprovado em 02 de outubro de 2009. Brasília: MEC/SEESP, 2009b. Disponível em: http://portal.mec.gov.br/ index.php?option=com_content $\&$ view=article $\& i d=13684 \% 3$ Aresolucoes-ceb$2009 \&$ catid $=323 \% 3$ Aorgaos - vinculados $\&$ Itemid $=866$. Acesso em 06 de novembro de 2009.

Ministério da Educação. Secretaria de Educação Especial, Decreto 6.571 de 17 de setembro de 2008. Brasília: MEC/SEESP, 2008.

- Ministério da Educação. Plano Nacional de Educação. Brasília: MEC, 2001. Disponível on-line em: http://portal.mec.gov.br/arquivos/pdf/ pne.pdf. Acesso em 10/01/2010. 
. Lei n. 9394, de 20 de dezembro de 1996. Estabelece as diretrizes e bases da educação nacional. Brasília, DF. 1996. Disponível em: <http://www.mec.gov.br/ seesp>. Acesso em: 30 mar. 2002.

. Lei n. 8069, de13 de julho de 1990.Dispõe sobre o estatuto da criança e do adolescente. Brasília:Senado Federal, 1990.

Constituição Federal do Brasil. Brasília: Senado Federal, 1988.

DELOU, Cristina Maria Educação do Aluno com Altas Habilidades/Superdotação: Legislação e políticas educacionais para a inclusão. In: FLEITH, Denise de Souza (org.) A construção de práticas educacionais para alunos com altas habilidades/superdotação. Volume 1: Orientação a professores. Brasília: MEC/ SEESP, 2007, p. 25-39.

FÁVERO O. ; HORTA J. S. B. ; FRIGOTTO G. Políticas educacionais no Brasil: desafios e propostas. Cadernos de Pesquisa, São Paulo, n.83, nov. 1992.

GERMANI, L. M. B. ; COSTA, M.R. N. da; VIEIRA, N. J. W. Proposta de política pública educacional para os alunos com altas habilidades/ superdotação no estado do Rio Grande do Sul. Revista Educação Especial, Santa Maria, n.28, p.209-217, 2006a.

Política pública educacional para pessoas portadoras de altas habilidades/superdotação no Rio Grande do Sul. In: FREITAS, S. N. Educação e altas habilidades/superdotação: a ousadia de rever conceitos e práticas. Santa Maria: Ed. da UFSM, 2006b, p.199-212

GIUGLIANI, S. Psicologia e políticas públicas. Entre Linhas, Conselho Regional de Psicologia do Rio Grande do Sul, Porto Alegre, mar./abr. 2007.

MATURANA, H. Emoções e linguagem na educação e na política. Belo Horizonte: Ed. da UFMG, 2001.

OUROFINO, V. T. A. T. de; GUIMARÃES, T. G. Características intelectuais, emocionais e sociais do aluno com altas habilidades/superdotação. In: FLEITH, D. de S. (Org.). A construção de práticas educacionais para alunos com altas habilidades/superdotação. v.1. Brasília: MEC/SEESP, 2007, p.41-51.

PRIETO, R. Políticas públicas de inclusão: compromissos do poder público, da escola e dos professores. Revista de Educação, Apeoesp, n. 16, mar. 2003. Disponível on-line em: http://www.google.com.br/\#hl=ptBR \& source $=h p \& b i w=1276 \& b i h=635 \& q=P$ ol $\%$ C 3\%ADticas $+p$ $\%$ C3\%BAblicas+de+inclus $\% \mathrm{C} 3 \% \mathrm{~A} 30 \% 3 \mathrm{~A}+$ compromissos+do+poder+p $\% \mathrm{C} 3 \% \mathrm{BA}$ b I i c o \% $2 \mathrm{C}+\mathrm{d} a+$ e s c o l $a+$ e + d o $s+$ profes sore $s . \& b$ tnG=Pesquisa+Google \&aq=f\&aqi=\&aql=\&oq=Pol\%C3\%ADticas $+p \%$ C $3 \%$ B Ablicas +de+inclus \% C $3 \%$ A 3 o\% $3 A+$ compromissos + do 
+ poder + p \% C 3\%BAblico $\% 2 C+d a+e s c o l a+e+d o s+p r o f e s s o r e s$ $. \& g s \_r f a i=\& f p=1 e b f 80 b 94 a c a 3 a 8 c$. Acesso em 10/01/2010.

Atendimento escolar para alunos com necessidades educacionais especiais: indicadores para análise de políticas públicas. Revista Undime, ano VIII, n. 1, 2002. Disponível on-line em: http://cappf.org.br/tikidownload_wiki_attachment.php?attld=396. Acesso em 10/01/2010.

. A construção de políticas públicas de educação para todos. Revista Educação on-line, 2001. Disponível em: http://www.educacaoonline.pro.br/ index.php?option=com_content\&view=article\&id=61:a-construcao-de-politicaspublicas-de-educacao-para-todos \&catid=5:educacao-especial\&ltemid=16. Acesso em: 10 jan. 2010.

RIO GRANDE DO SUL, Constituição do Estado do Rio Grande do Sul. Porto Alegre: Assembléia Legislativa. 1989. Disponível em: http://www.al.rs.gov.br/ prop/Legislacao/Constituicao/constituicao.htm\#T07C02S01. Acesso em: 13 jan. 2010.

\footnotetext{
Notas

${ }^{1}$ Fundação de Articulação e Desenvolvimento de Políticas Públicas para Pessoas Portadoras de Deficiências e Altas Habilidades no Rio Grande do Sul.

${ }^{2}$ Essa denominação foi instituída pela equipe técnica da FADERS, responsável pela elaboração da política. A introdução dessa nomenclatura se justificou pelo sentido excludente e pejorativo impregnado em algumas escolas pelas chamadas "salas de recursos para superdotados".

${ }^{3}$ Conselho Brasileiro para Superdotação.

${ }^{4}$ Associação Gaúcha de Apoio às Altas Habilidades/Superdotação.
}

\section{Correspondência}

Nara Joyce Vieira - Rua Barão do Amazonas, 622. Bairro Centro. Alegrete-RS Cep 97542-100 Email: najevars@yahoo.com.br

Recebido em 08 de junho de 2010

Aprovado em 13 de agosto de 2010 